\title{
Premature termination of the sympathetic chain
}

\author{
Y. Mansour'1, 2®, R.J. Kulesza10 \\ ${ }^{1}$ Department of Anatomy, Lake Erie College of Osteopathic Medicine, Erie, PA, United States \\ 2Department of Otolaryngology-Facial Plastic Surgery, Henry Ford Macomb Hospital, Clinton Twp, MI, United States
}

[Received: 22 May 2021; Accepted: 26 July 2021; Early publication date: 15 September 2021]

\begin{abstract}
The sympathetic chain serves to distribute visceral efferents and afferents over the entire body. The sympathetic chain courses from the base of the skull to the coccyx and sends branches to distribute along spinal nerves and a number of visceral nerves that distribute to cardiac muscle, smooth muscle and glands. During dissection of the posterior abdominal wall, we identified a rare variation of the sympathetic chain. In this subject, the sympathetic chain failed to send grey rami to the L2-4 spinal nerves and terminated by joining the S1 anterior ramus. Such a variation has only been reported once in the literature in 1895. We provide both schematic and photographic documentation of this variation and propose a number of possible circuits whereby visceral axons can reach their target despite these anatomical barriers. (Folia Morphol 2022; 81, 4: 1054-1057)
\end{abstract}

Key words: anatomy, neuroscience, neuroanatomy, human body

\section{INTRODUCTION}

The sympathetic component of the autonomic nervous system includes an efferent chain of two neurons and axons of primary afferent neurons. The first of the two efferent neurons, the preganglionic or presynaptic neurons, have cell bodies in the interomediolateral cell column (IML CC) in the spinal cord [3]. The IML CC extends from the first thoracic segment to the $2^{\text {nd }}$ or $3^{\text {rd }}$ lumbar segment [3]. The second of these two neurons, the postganglionic or postsynaptic neuron, has a cell body in a peripheral ganglion, either the sympathetic chain or ganglia situated anterior to the aorta in the abdominopelvic cavity [3]. Coursing with these efferent axons are afferent axons derived from neurons in the posterior root ganglia from the same levels (T1-L2) [12].

The sympathetic chain serves as a superhighway for distribution of both efferent and afferent axons concerned with innervation of glands, smooth and cardiac muscle literally everywhere in the entire body [12].
The sympathetic chain extends from the base of the skull [3], although there are reports of a ganglion cells across anterior communicating artery (ganglion of Ribes) [13], to the tip of the coccyx at the ganglion impar (coccygeal ganglion of Luschka). The sympathetic chain receives white rami from the T1-L2 spinal nerves (Fig. 1). Some resources state white rami are found at C8-L3 spinal nerves [15]. These white rami transmit preganglionic sympathetic efferent axons from cell bodies in the IML CC and afferent axons from pseudounipolar neurons in posterior root ganglia at spinal levels T1-L2 [12]. Through additional rami the sympathetic chain innervates portions of the vertebral column and associated ligaments [7]. A number of visceromotor ganglia are situated along the course of the sympathetic chain (Fig. 1). In the cervical region there are only 3 to 4 ganglia, but in the thoracic, lumbar and sacral regions there are typically chain ganglia at every spinal level [3]. Some reports state there may be only 3-4 lumbar ganglia

Address for correspondence: Dr. R.J. Kulesza, Department of Anatomy, Lake Erie College of Osteopathic Medicine, 1858 West Grandview Blvd, Erie, PA 16509, USA, tel: 814-866-8423, e-mail: rkulesza@lecom.edu

This article is available in open access under Creative Common Attribution-Non-Commercial-No Derivatives 4.0 International (CC BY-NC-ND 4.0) license, allowing to download articles and share them with others as long as they credit the authors and the publisher, but without permission to change them in any way or use them commercially. 


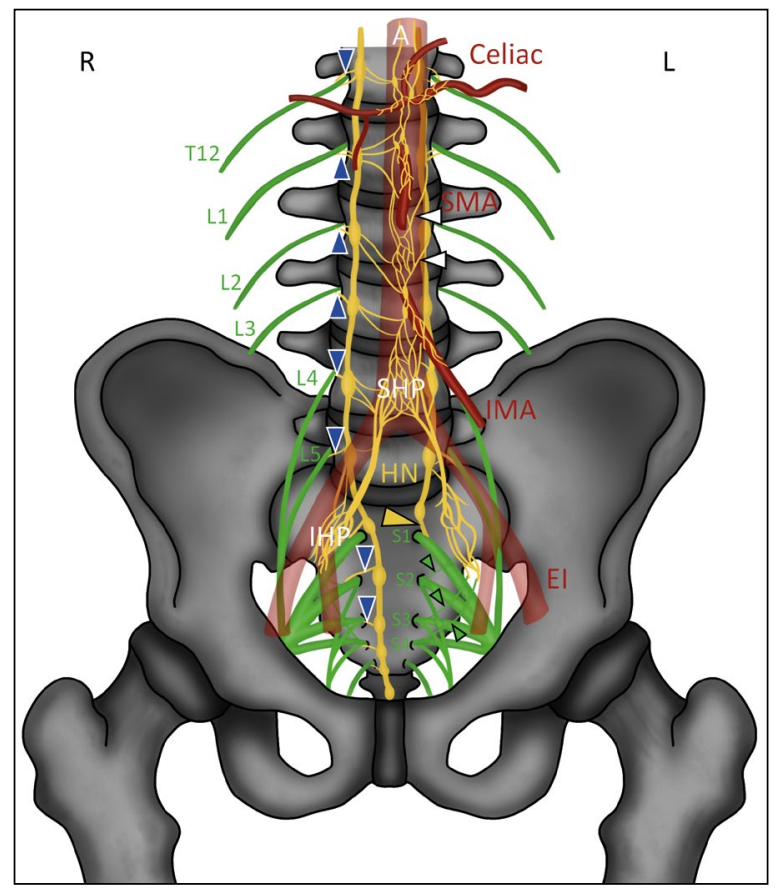

Figure 1. Branching from the subdiaphragmatic sympathetic chain. Shown on the subject's right side $(\mathrm{R})$ is the normal pattern of branching from the sympathetic chain (yellow). This includes white and grey rami to the T12-L2 and grey rami to the remaining ventral rami (blue arrowheads), lumbar splanchnic (white arrowheads) and sacral splanchnic nerves. Preaortic ganglia are found at the roots of the coeliac, superior mesenteric (SMA) and inferior mesenteric arteries (IMA). The superior hypogastric plexus (SHP) distributes sympathetics to pelvic organs via hypogastric nerves (HN) and the inferior hypogastric plexus (IHP). Note the sympathetic chain continues all the way to the coccyx. The left side (L) shows the pattern found in this case study. Specifically, note the sympathetic chain fails to send branches to the ventral rami L2-4 and terminates by joining the $S 1$ ventral ramus (yellow arrowhead). Pelvic splanchnic nerves are indicated by green arrowheads; A — aorta; El — external iliac.

with that of the $L 5$ level being the most consistent $[5,15]$.

The sympathetic chain forms numerous branches to distribute efferent and afferent axons. Specifically, the sympathetic chain sends grey rami carrying postganglionic efferents and primary afferent axons into each spinal nerve (Fig. 1) [12]. For the lower extremity, preganglionic cell bodies are located in the IML CC at T10-L2 and the efferents are situated in posterior root ganglia at the same spinal levels [12].

A number of branches distribute postganglionic efferents and primary afferents including the internal carotid nerve, the external carotid nerve, and numerous branches distributing to the pharynx, larynx, and thoracic organs. Additionally, there are numerous splanchnic nerves (greater, lesser, least, lumbar and sacral) that distribute preganglionic efferents and primary afferents to preaortic ganglia and plexi in the abdominopelvic cavities (Fig. 1) [12].

While there are numerous reported variations of the cervical and thoracic sympathetic trunk, reports on variation of the lumbar or sacral aspects of the sympathetic chain, including abnormal termination are extremely rare $[2,9,13,14]$. There is a report of lumbar splanchnic nerves intermingling with gonadal vessels [11]. Webber reports possibilities of accessory sympathetic ganglia that may or may not connect to the sympathetic chain [5]. Another report details an accessory hypogastric nerve and an additional pelvic splanchnic nerve originating from the $\mathrm{S} 1$ sacral root [1]. There is a single report of a sympathetic chain terminating prematurely by joining one of the sacral anterior rami [4]. In this report, the right sympathetic chain terminated by entering the anterior aspect of the $\$ 2$ anterior ramus directly anterior to the S2 sacral foramen. Only one sacral ganglion was present and this was found anterior to the S1 anterior ramus. However, this report included only a brief description and unfortunately no images of the variation.

\section{CASE REPORT}

The specimen used in this case report was obtained through the Humanity Gifts Registry of Pennsylvania (USA) and was used in accordance with its educational mission.

Dissection of the posterior abdominal wall of a 60-year-old male (cause of death: natural death, failure to thrive, severe general debility, severe generalised atherosclerosis, and coronary artery disease) in the Anatomy Lab at the Lake Erie College of Osteopathic Medicine revealed a peculiarity of the sympathetic chain. Specifically, on the left side of the body, the sympathetic chain was found to form a number of lumbar splanchnic nerves (Figs. 1, 2, white arrowheads) that ran anterior, inferior and medial to join the superior hypogastric plexus (Fig. 2). The sympathetic chain continued along the posterior abdominal wall and ran posterior to the common iliac artery and vein. The chain contributed a large grey ramus (Fig. 2, red arrowhead) to the $\mathrm{L} 5$ anterior ramus and then terminated by joining the anterior aspect of the $\mathrm{S} 1$ anterior ramus (Fig. 1, yellow arrowhead; Fig. 2, yellow wire). No grey rami were found to join the ventral rami of $L 2-4$.

\section{DISCUSSION AND CONCLUSIONS}

Formation of the sympathetic chain begins around embryonic days 30-36 from neural crest cells along the 


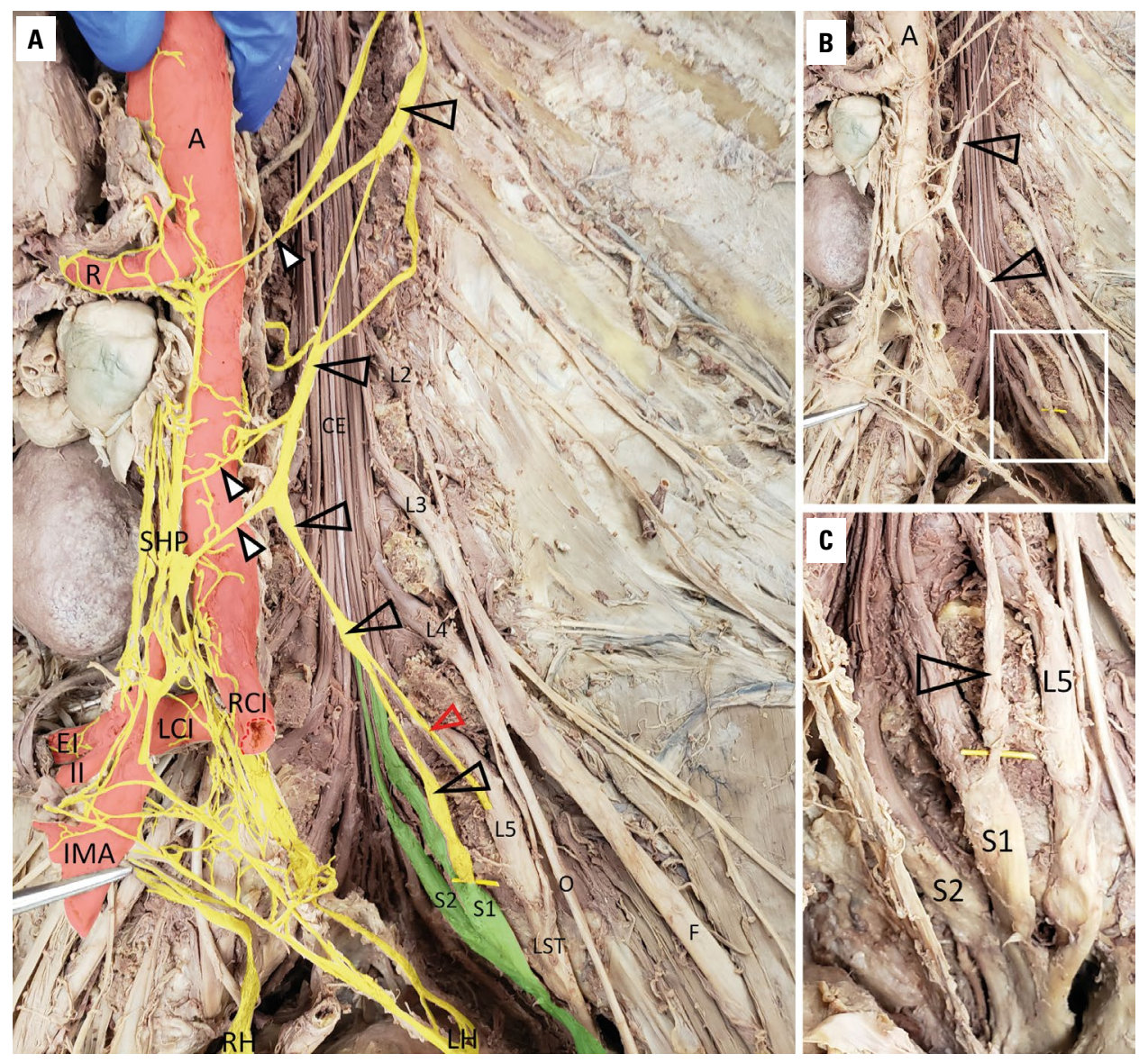

Figure 2. Branches and distribution of the left sympathetic chain. A colourised view of the sympathetic chain and plexus is shown in panel $\mathbf{A}$; an uncoloured version is shown in panel $\mathbf{B}$. The aorta $(A ;$ red) is lifted and rotated to the right to show the branches from the sympathetic chain (arrowheads). All of the sympathetic branches are coloured in yellow. A number of lumbar splanchnic nerves (white arrowheads) are seen to join the superior hypogastric plexus (SHP). A grey ramus (red arrowhead) joins the L5 anterior ramus. In panels $\mathbf{A}$ and $\mathbf{B}$, the sympathetic chain joins the anterior ramus of $S 1$ (yellow wire). The union of the sympathetic chain and $S 1$ is shown enlarged in panel $\mathbf{C}$; $\mathrm{CE}-\mathrm{cau}-$ da equina; EI — external iliac; $\mathrm{F}$ — femoral nerve; II — internal iliac; IMA — inferior mesenteric artery; LCI — left common iliac; $\mathrm{LH}$ — left hypogastric nerve; LST — lumbosacral trunk; $\mathrm{O}$ - obturator nerve; $\mathrm{R}$ - renal artery; $\mathrm{RH}$ - right hypogastric nerve; $\mathrm{RCI}$ — right common iliac.

dorsolateral aspect of the developing spinal cord; these cells differentiate into catecholaminergic ganglionic neurons destined for the sympathetic chain $[10,17]$. By embryonic days 37-39, the sympathetic chain expands and forms connections with preganglionic sympathetic nerve fibres [10]. By embryonic day 44, the ganglionic cells begin to condense and form ganglia at each segmental or spinal level [10]. The ganglia and chain continue to grow and mature throughout gestation to distribute sympathetic axons throughout the body [16]. The variation found in this case report constitutes an abnormal connection of the sympathetic chain that most likely arose during early embryonic development. While this finding appears to be extremely rare, it nonetheless results in an abnormal pattern of innervation from the lumbar sympathetic chain and could contribute to surgical complications during approaches to the lumbar spine $[6,7,18]$.
Sympathetics distribute everywhere in the entire body through three basic circuits. Sympathetics distribute to the body wall via the sympathetic chain and grey rami that join the spinal nerves and/or ventral rami and distribute along peripheral nerves to smooth muscles and glands [12]. Distribution to organs in the head, neck and thoracic cavities involve postganglionic branches from the sympathetic chain [12]. Finally, sympathetics distribute to abdominopelvic organs via splanchnic nerves, preaortic ganglia and the hypogastric plexus [12]. The subject of this case study had no sympathetic chain below $\mathrm{S} 1$ on the left and as such, no sacral splanchnic nerves on the left side (Fig. 1). Our interpretation of this anatomical variation is based on two assumptions. First, that sympathetics go everywhere and second, that the body is always right. Therefore, we believe that despite this anatom- 
ical variation, the body finds routes or connections to distribute sympathetics to all the organs, vessels and skin and that the novel pathways in this subject were functional. Accordingly, sympathetic innervation to the abdominopelvic viscera was likely achieved by the lumbar splanchnic nerves and the hypogastric plexus.

More complicated though, this subject also had no grey rami from L2-4 and below S1 (Figs. 1, 2). The grey rami joining $\mathrm{L} 5$ and $\mathrm{S} 1$ on the right side were large. We suspect these grey rami distributed postganglionic sympathetic axons and visceral afferents across all sacral and coccygeal dermatomes. We propose three possible routes for this to occur. First, that axons from the grey rami joining the L 5 and S1 rami distributed into the sacral plexus and coursed retrograde into $\mathrm{S} 3$ through coccygeal levels and then followed these nerves to the body wall. Alternatively, axons from these grey rami may follow branches from the sacral plexus (to S2) and then overstep their dermatome boundaries in the skin to supply skin in S3, S4, S5 and coccygeal dermatomes. Finally, it is possible that axons from the lumbar splanchnic nerves on the right side course through the mesenteric and hypogastric plexi, hypogastric nerves and inferior hypogastric plexus and then course retrograde through pelvic splanchnic nerves (Fig. 1, green arrowheads) to join the ventral rami of S2-4. Regardless of the pathway employed in this subject, we believe all of the smooth muscle and glands in the sacral and coccygeal dermatomes receive sympathetic innervation.

\section{Acknowledgements}

The authors sincerely thank those who donated their bodies to science so that anatomical research could be performed. Results from such research can potentially increase mankind's overall knowledge that can then improve patient care. Therefore, these donors and their families deserve our highest gratitude [8].

\section{Conflict of interest: None declared}

\section{REFERENCES}

1. Aurore $V$, Röthlisberger $R$, Boemke $N$, et al. Anatomy of the female pelvic nerves: a macroscopic study of the hypogastric plexus and their relations and variations. J Anat. 2020; 237(3): 487-494, doi: 10.1111/joa.13206, indexed in Pubmed: 32427364.

2. Bergman RA, Thompson SA, Afifi AK. Compendium of human anatomic variation: text, atlas, and world literature. Urban \& Schwarzenberg, Germany 1988.
3. Crosby EC, Humphrey T, Lauer EW. Correlative Anatomy of the Nervous System. 1st Ed. The Macmillan Company, New York, NY 1962.

4. Fawcett E. An unusual mode and site of termination of the right sacral sympathetic cord. J Anat Physiol. 1895; 29(Pt 2): 329, indexed in Pubmed: 17232132.

5. Gandhi KR, Verma VK, Chavan SK, et al. The morphology of lumbar sympathetic trunk in humans: a cadaveric study. Folia Morphol. 2013; 72(3): 217-222, doi: 10.5603/ fm.2013.0036, indexed in Pubmed: 24068683.

6. Guérin $P$, Obeid I, Bourghli $A$, et al. The lumbosacral plexus: anatomic considerations for minimally invasive retroperitoneal transpsoas approach. Surg Radiol Anat. 2012; 34(2): 151-157, doi: 10.1007/s00276-011-0881-z, indexed in Pubmed: 21971645.

7. Higuchi K, Sato T. Anatomical study of lumbar spine innervation. Folia Morphol. 2002; 61(2): 71-79, indexed in Pubmed: 12164053.

8. Iwanaga J, Singh V, Ohtsuka A, et al. Acknowledging the use of human cadaveric tissues in research papers: Recommendations from anatomical journal editors. Clin Anat. 2021; 34(1): 2-4, doi: 10.1002/ca.23671, indexed in Pubmed: 32808702.

9. Jain $P$, Raza K, Singh S, et al. Lumbar sympathetic chain: anatomical variation and clinical perspectives. Clin Ter. 2016; 167(6): 185-187, doi: 10.7417/CT.2016.1970, indexed in Pubmed: 28051823.

10. Kruepunga N, Hikspoors JP, Hülsman CJM, et al. Development of the sympathetic trunks in human embryos. J Anat. 2021; 239(1): 32-45, doi: 10.1111/joa.13415, indexed in Pubmed: 33641166.

11. Murata $Y$, Takahashi $K$, Yamagata $M$, et al. Variations in the number and position of human lumbar sympathetic ganglia and rami communicantes. Clin Anat. 2003; 16(2): 108-113, doi: 10.1002/ca.10069, indexed in Pubmed: 12589664

12. Standring S. Gray's Anatomy: The anatomical basis of clinical practice. 40th Ed. Elsevier, London, UK 2008.

13. Tubbs RS, Kelly DR, Shoja MM, et al. Does the ganglion of Ribes exist? Folia Neuropathol. 2006; 44(3): 197-201, indexed in Pubmed: 17039415.

14. Tubbs RS, Shoja MM, Loukas M. Bergman's Comprehensive Encyclopedia of Human Anatomic Variation. 1st Ed. Hoboken, NJ 2016.

15. Webber RH. An analysis of the sympathetic trunk, communicating rami, sympathetic roots and visceral rami in the lumbar region in man. Ann Surg. 1955; 141(3): 398-413, doi: 10.1097/00000658-195503000-00016, indexed in Pubmed: 14350582.

16. Woźniak W. The lumbar part of the sympathetic trunk in human fetuses and newborns. Anat Anz. 1969; 125(3): 289-295, indexed in Pubmed: 5364597.

17. Woźniak W, Grzymisławska M, Lupicka J. The first appearance of sympathetic ganglia in human embryos at stage 13. Folia Morphol. 2009; 68(4): 215-217, indexed in Pubmed: 19950069.

18. Żytkowski A, Tubbs R, Iwanaga J, et al. Anatomical normality and variability: Historical perspective and methodological considerations. Trans Res Anat. 2021; 23: 100105 , doi: 10.1016/j.tria.2020.100105. 